\title{
Sacral Stress Fracture due to Excess Weight Gain during Pregnancy while Self-Quarantining during the COVID-19 Pandemic
}

\author{
Rıfat Sahin \\ Department of Orthopaedia and Traumatology, Recep Tayyip Erdogan University, Rize, Turkey
}

\begin{abstract}
Most pregnancy-related sacral stress fractures occur after delivery. This case aims to emphasise that stress fractures can occur before delivery, and since excessive weight gain is a risk factor, pregnant women should avoid gaining excess weight, especially during quarantine.

This patient, who gained 20 kgs during first pregnancy, started complaining of severe pain in the left sacral region in the 40 th week of pregnancy, without any trauma. Despite conservative follow-up, her pain increased, and a caesarean section was performed. The patient continued to complain of pain in the left sacral region. Magnetic resonance imaging (MRI) identified a sacral stress fracture which was treated conservatively and resolved after 4 months.

Complaints of severe back pain during the last stage of pregnancy require a detailed physical examination. When localised sensitivity is detected in the sacral region during pregnancy, a diagnosis can be made using MRI, thereby avoiding radiation exposure.
\end{abstract}

Key Words: Stress fractures, COVID-19, Sacrum, Pregnancy.

How to cite this article: Sahin R. Sacral Stress Fracture due to Excess Weight Gain during Pregnancy while Self-Quarantining during the COVID-19 Pandemic. J Coll Physicians Surg Pak 2021; 31(JCPSPCR):CR127-CR129.

\section{INTRODUCTION}

Waist and hip pain are common during pregnancy and after childbirth. Sacral stress fractures are a rare cause of this pain. Typically seen in the elderly, the etiology of such fractures includes osteoporosis, rheumatoid arthritis, Paget's disease, hyperparathyroidism, metastasis, and radiotherapy for malignancy. ${ }^{1}$ Stress fractures are also more common in long-distance runners than in the normal population. ${ }^{2}$

Pentecost and colleagues described stress fractures in 1964 as follows: Partial or complete fractures occurring as a result of the bone's inability to withstand stress due to rhythmic loads below the threshold that would cause the fracture. They divided stress fractures into fatigue and insufficiency fractures. While fatigue fractures occur because of unusual repetitive mechanical stress on normal bone, insufficiency fractures involve deterioration of the bone structure with fractures occurring even under normal stress. ${ }^{3}$

Correspondence to: Dr. Rifat Sahin, Department of Orthopaedia and Traumatology, Recep Tayyip Erdogan University, Rize, Turkey

E-mail: drrifatsahin@hotmail.com

Received: November 03, 2020; Revised: April 26, 2021; Accepted: May 02, 2021

DOI: https://doi.org/10.29271/jcpsp.2021.JCPSPCR.CR127
Since the sacral stress fracture was described by Laurie in 1982, a small number of pregnancy-related sacral fractures have been reported in the literature. ${ }^{4}$ Most of these cases have been described as postpartum fractures. Since sacral stress fractures often develop after birth, prenatal fractures can be missed. By presenting this case, we aim to emphasisethe importance of controlled weight gain in pregnant women by drawing attention to the fact that sacral stress fractures may be the cause of sudden back pain, which develops in the last trimester.

\section{CASE REPORT}

A 24-year primigravid patient, who had an active life before pregnancy, became pregnant in January 2020. Due to COVID-19 pandemic, she first practised social isolation and then home quarantine during the second half of pregnancy. The patient, whose mobilisation was very limited, started to eat more due to stress and gained a total of $20 \mathrm{Kgs}$ during pregnancy. She was $1.68 \mathrm{~m}$ tall and weighed $58 \mathrm{Kgs}$ before pregnancy, and $78 \mathrm{Kgs}$ prior to giving birth with a body mass index (BMI) increase from 20.5 to 27.6. She started to experience severe pain in left sacral region without any trauma at 40 weeks and 1 day into her pregnancy. The pain increased with walking and lying on back, and was relieved by lying on side and sitting. When the pain prevented mobilisation, she sought the advice of obstetrician. Ultrasonography revealed no pathology. The patient was told that such pains at theend of pregnancy may be due to physiological and psychological reasons. After four days, the pain wors- 
ened, and she was taken immediately for delivery. At 40 weeks and 5 days, she delivered a 3.9 Kgs healthy male baby by caesarean section without difficulties.

When the pain in the sacral region continued, she came to our clinic on the 6th day after delivery. A physical examination revealed tenderness with palpation at the S1-2 location of the left sacral region, which did not spread to the legs. Neurological deficits were not detected and a Laségue test was negative. Hip movements were painless. FABER and FADIR tests were positive. There was an unsupported but antalgic gait pattern with short steps identified, but no malalignment in the spine. Her visual analogue scale scores were 10 prenatal and 7 postnatal.

Since the patient was still in the breastfeeding period, magnetic resonance imaging (MRI) was performed to avoid exposure to ionizing radiation. On the left side of the sacrum, a hypo-intense (on T1) and hyper-intense (on T2) vertical extension non-displaced fracture at $\mathrm{T} 1$ with extensive bony oedema were observed consistent with a stress fracture of the sacrum (Figure I). There was no previous history of fractures.

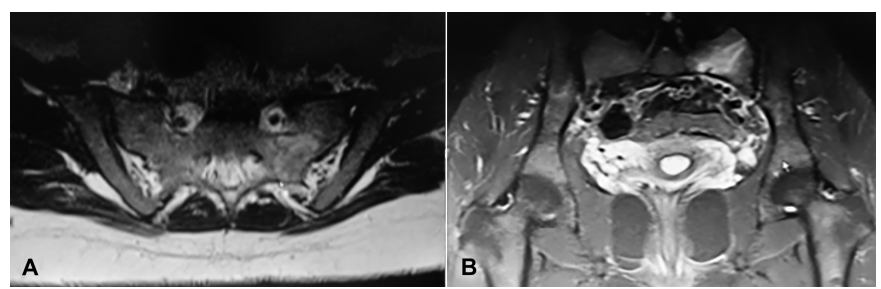

Figure I: (A, B) Hypo-intense (on T1) and hyper-intense (on T2) vertical extension nondisplaced fracture and surrounding bone oedema in the left sacrum on MRI.

Table l: Haematological and biochemical results at the time of sacral fracture diagnosis.

\begin{tabular}{|l|l|l|l|}
\hline Parameters & Results & Reference & Units \\
\hline Haemoglobin & 14.1 & $11-16$ & $\mathrm{~g} / \mathrm{dL}$ \\
\hline White cell count & 12.06 & $4-10$ & $10^{\wedge} 3 / \mathrm{uL}$ \\
\hline Platelets & 384 & $100-400$ & $10^{\wedge} 3 / \mathrm{uL}$ \\
\hline Sedimentation (1 hour) & 7 & $0-20$ & $\mathrm{~mm} / \mathrm{h}$ \\
\hline Rheumatoid factor & $<10$ & $0-14$ & $\mathrm{IU} / \mathrm{mL}$ \\
\hline Serum alkaline phosphatase & 84 & $33-98$ & $\mathrm{U} / \mathrm{L}$ \\
\hline Lactate dehydrogenase & 182 & $0-248$ & $\mathrm{U} / \mathrm{L}$ \\
\hline Serum creatine kinase (CK) & 68 & $0-145$ & $\mathrm{U} / \mathrm{L}$ \\
\hline Serum calcium & 9.8 & $8.8-10.6$ & $\mathrm{mg} / \mathrm{dL}$ \\
\hline Serum urea & 15 & $17-43$ & $\mathrm{mg} / \mathrm{dL}$ \\
\hline Serum creatinine & 0.46 & $0.51-0.95$ & $\mathrm{mg} / \mathrm{dL}$ \\
\hline Serum albumin & 36.9 & $35-52$ & $\mathrm{~g} / \mathrm{L}$ \\
\hline Serum 25-hyroxyvitamin D & 20.3 & $6.6-49.9$ & $\mathrm{ng} / \mathrm{mL}$ \\
\hline
\end{tabular}

The patient did not give a history of chronic disease, digestive disorder, malabsorption, or an eating problem such as anorexia, and had no smoking, alcohol, drug, or steroid use, vitamin deficiency, or trauma history. She did not have an infection or medication history during pregnancy and did not use prenatal anticoagulants. There was no familial history of osteoporosis. In the bone mineral density (BMD) measurement detected by dualenergy $x$-ray absorptiometry (DEXA), the $T$ and $Z$ score of the lumbar region was -0.1 , while the $T$ and $Z$ score of the left femur was -0.8 , and within normal limits. Blood analysis results were within normal ranges except for a slightly high white cell count and a slightly low serum urea and creatine (Table I).
Oral calcium and vitamin D were started for treatment without interrupting breastfeeding. The patient was advised to use paracetamol $3 \times 500 \mathrm{mg}$ when needed for pain relief. Bed rest was recommended for the first 2 weeks with sitting allowed but not upright. Low molecular weight heparin was prescribed as an anticoagulant for 2 weeks. At the end of 2 nd week, the patient had a partial reduction in pain and was mobilised with one side support. By the 6th week, her pain decreased considerably, and she was mobilised without any support. She had no complaints by the end of 4 th month.

\section{DISCUSSION}

Stress fractures of the sacrum are rare in the young population with most issues in teens, occurring in long-distance runners and pregnant women. ${ }^{2}$ Risk factors for pregnancy-related sacral fractures are excessive weight gain, postmaturity, rapid vaginal delivery, increased lumbar lordosis, use of forceps, vitamin D deficiency, decreased bone mineralisation, and heparin use. ${ }^{4}$ The only stress fracture risk factors identified in this patient were excessive weight gain and possible late term delivery. Due to the risk of coronavirus transmission, the patient who spent most of her time at home in the last trimester stated that her mobilization was restricted, and she ate more due to stress. Zachary et al., in their study involving 1,200 people, found that $91 \%$ of people spent more time at home since the COVID-19 pandemic began and $22 \%$ had gained $5-10$ pounds during the pandemic. ${ }^{5}$

Maternal weight gain is one of the most prominent changes during pregnancy. Average weight gain should be in the range of 10-13 Kgs. The ideal weight gain values for underweight, normal weight, overweight, and obese women are 12.5-18, 11.5-16, 7-11.5, and 5-9 Kgs, respectively. ${ }^{6}$ Our patient's prepregnancy BMI was 20.5 and she was at a normal weight, thus her ideal pregnancy weight gain would have been 11.5-16 Kgs. She gained $20 \mathrm{Kg}$ during the pregnancy and we believe that a fatigue fracture occurred because of prolonged exposure of the pelvis to this increased load. To reduce the occurrence of fatigue fractures, pregnant women should be educated about the benefits of physical activity and personalised exercise programmes should be developed. Pregnant women who are in home quarantine during the pandemic should be informed about the importance of movement.

Genetic factors are also involved in stress fracture etiology. ${ }^{7}$ The mother of the patient, who was not diagnosed, had similar pains in the same area, which decreased after birth but continued for 6 months. This suggests that there may be patients who have been followed-up for a long time with a recommendation for analgesics and rest without having been given a proper diagnosis. There are very few cases of prenatal sacral stress fractures in the literature. These cases are typically diagnosed after birth, as in this patient, or not at all. It is very important to determine the location of low back and hip pain that begins late in pregnancy or after childbirth by conducting a physical examination. MRI should be used to rule out stress fractures before considering physiological and psychological reasons, espe- 
cially in patients with excessive weight gain in the last stage of pregnancy who experience sudden severe back pain without any trauma.

Sacral stress fractures should not be confused with hip avascular necrosis in pregnancy. The pain associated with a sacral stress fracture increases with activity and decreases with rest. ${ }^{7}$ Delay in diagnosis not only extends the duration of the pain but may also cause the fracture to grow or radicular symptoms to develop. ${ }^{8}$ Sacral stress fractures should not be ignored in the differential diagnosis of sudden back pain and abnormal gait during the last stage of pregnancy or after childbirth.

Since stress fractures are usually thin and nondisplaced, they can be missed on radiography. MRI is the gold standard imaging tool, as it does not emit ionizing radiation and recognizes occult fractures by showing bone oedema. ${ }^{9}$ Brahme described the typical image of a sacral stress fracture on MRI as follows: Broad bands with low signal intensity running parallel to the sacral ala in T1 and T2 fat-saturated STIR sequences. In addition, Bone oedema around the fracture line represents the severity of the fracture and is observed as hypointense at $\mathrm{T} 1$ and hyperintense atT2 infat-saturated/STIR images. ${ }^{9}$

DEXA can be used to differentiate these fractures by determining BMD. ${ }^{10}$ In a literature review of sacral stress fractures, only $16.6 \%$ of patients showed a decrease in BMD. ${ }^{2}$ Once a sacral stress fracture is diagnosed, we recommend DEXA imaging and further investigation for possible underlying metabolic diseases.

Excess weight gain is the leading risk factor for stress fractures during pregnancy. During the COVID-19 pandemic, quarantine, and social isolation, lead to restrictions in the mobility of individuals, and weight gain may occur as a result of overeating due to stress. Expectant mothers should be given a personalised exercise program and proper nutrition training; otherwise, more rare sacral stress fractures may occur.

\section{PATIENT'S CONSENT:}

Informed consent was obtained from the patient.

\section{CONFLICT OF INTEREST:}

The author declared no conflict of interest.

\section{AUTHOR'S CONTRIBUTION:}

RS: Writing report, diagnosis and treatment.

\section{REFERENCES}

1. Karataş M, Başaran C, Özgül E, Tarhan C, Ağildere AM. "Postpartum sacral stress fracture: an unusual case of lowback and buttock pain," Am J Phys Med Rehabil 2008; 87(5):pp. 418-22. doi: 10.1097/PHM.0b013e318164a8e6.

2. Speziali A, Tei MM, Placella G, Chillemi M, Cerulli G. Postpartum sacral stress fracture: An atypical case report. Case Rep Orthop 2015; 2015:704393. doi: 10.1155/ 2015/704393.

3. Pentecost RL, Murray RA, Brindley HH. Fatigue, insuffıcıency, and pathologıc fractures. Jama 1964; 187: 1001-4. Doi: 10.1001/jama.1964.03060260029006. Pmıd: 14102934.

4. Hilal N, Nassar AH. Postpartum sacral stress fracture: A case report. BMC Pregnancy Childbirth 2016; 16:96. doi: 10.1186/s12884-016-0873-4.

5. Zachary Z, Brianna F, Brianna L, Garrett P, Jade W, Alyssa $D$, et al. Self-quarantine and weight gain related risk factors during the COVID-19 pandemic. Obes Res Clin Pract 2020; 14(3):210-16. doi: 10.1016/j.orcp.2020.05.004.

6. Frederick IO, Williams MA, Sales AE, Martin DP, Killien M. Pre-pregnancy body mass index, gestational weight gain, and other maternal characteristics in relation to infant birth weight. Matern Child Health J 2008; 12(5):557-67. doi: 10.1007/s10995-007-0276-2.

7. Yan CX, Vautour L, Martin MH. Postpartum sacral insufficiency fractures. Skeletal Radiol 2016; 45(3):413-7. doi: 10.1007/s00256-015-2289-z.

8. Malherbe JAJ, Davel S. An atraumatic sacral fracture with lumbosacral radiculopathy complicating the early postpartum period: A case report. Am J Case Rep 2019; 20:794-9. doi: 10.12659/AJCR.915764.

9. Brahme SK, Cervilla V, Vint V, Cooper K, Kortman K, Resnick D. Magnetic resonance appearance of sacral insufficiency fractures. Skeletal Radiol 1990; 19(7):489-93. doi: 10.1007/BF00202696.

10. Schildhauer TA. Commentary on: "Atraumatic sacral fracture in late pregnancy: A case report". Global Spine J 2015; 5(3):252. doi: 10.1055/s-0035-1549442. 